\title{
HÉRNIA UMBILICAL GIGANTE EVISCERADA: RELATO DE CASO
}

\section{UMBILICAL EVISCERATED GIANT HERNIA: CASE REPORT}

DOI: $10.5380 /$ rmu.v1i4.40696

Gustavo de Souza Arantes Ferreira ${ }^{1}$, Thaisa Nakadomari ${ }^{1}$, Fernanda Lika Tabushi ${ }^{2}$, Felipe Ioshio Tabushi ${ }^{2}$, Daniela

Maria Rosário Marques ${ }^{1}$, Benur Polonio ${ }^{1}$.

\section{RESUMO}

O tratamento cirúrgico nas hérnias umbilicais gigantes complicadas (obstrução, evisceração e/ou contaminação) consiste muitas vezes em tratar a complicação em uma primeira cirurgia e posteriormente corrigir o grande defeito na parede abdominal utilizandose uma tela de reforço. Relata-se o caso de uma paciente com hérnia umbilical gigante eviscerada no qual se realizou a cirurgia em um tempo com reforço da parede com tela, discute-se os aspectos do caso e a literatura atual..

Palavras-Chave: hérnia umbilical, herniorrafia.

\begin{abstract}
Surgical treatment of complicated giant umbilical hernias (obstruction, infection) was to treat complication first and during a second surgery reinforced the abdominal wall with a non-absorbable prosthesis. In this case the patient has an eviscerated giant umbilical hernia, the operation performed was dissection of the hernia sac wall with resection of omentum. The abdominal wall was reinforced with a non-absorbable prosthesis. Others authors agreed with the use of non-absorbable prosthesis in cases with potentially contaminated surgery provided careful surgery technique is used so to minimize infection risks, combined with a suitable designed antibiotic regime.
\end{abstract}

Key-Words: umbilical hernia, herniorrhaphy. 


\section{INTRODUÇÃO}

As hérnias umbilicais tem prevalência de 3 a $13,9 \%$, sendo que 0,5 a $15 \%$ necessitam de cirurgia de urgência por complicações, com uma taxa de mortalidade de 4,5 a $13,5 \%^{1-3}$. Com o desenvolvimento de novas técnicas, as próteses (telas) proporcionaram a correção de hérnias sem tensão, estas revolucionaram a cirurgia de hernioplastias e reduziram a taxa de recidiva. Apesar de seus benefícios em cirurgias eletivas, seu uso ainda não é bem definido em cirurgias de urgência/emergência ${ }^{4-6}$.

\section{RELATO DO CASO}

Paciente do sexo feminino, 54 anos, foi atendida no Serviço de Urgência e Emergência do Hospital de Clínicas da UFPR, por queixas de dor abdominal e secreção fétida abdominal associada à hérnia umbilical gigante (Figura 1). Tinha como comorbidades diabetes melitus tipo 2, hipertensão arterial, hipotireoidismo e amaurose bilateral decorrente de meningite aos 17 anos. Ao exame apresentava hérnia umbilical gigante primária cuja extremidade atingia o terço distal da coxa com área de evisceração com exposição de segmento de intestino delgado. Foi realizada uma tomografia abdominal entre os exames pré-operatórios (Figura 2). Indicou-se tratamento cirúrgico e hernioplastia. Durante o ato operatório, realizou-se a dissecção do saco herniário, apendicectomia, omentectomia e ressecção de excesso de tecido da parede abdominal incluindo a porção ulcerada. Como o defeito na aponeurose abdominal era grande, colocou-se uma tela de márlex, mesmo com a contaminação da parede abdominal. Utilizou-se ceftriaxona e metronidazol como profilaxia antibiótica que foi continuado no pós-operatório (Figura 3). A paciente evoluiu com restrição ventilatória até o 30 dia de pós-operatório, permanecendo na UTI até 16ㅇdia. Neste período apresentou infecção de subcutâneo sendo feito tratamento local. Teve alta da UTI no 170 P.O. e alta hospitalar no dia seguinte, e encontra-se sem complicações em acompanhamento ambulatorial com 8 meses e boa evolução.

\section{DISCUSSÃO}

Desde seu surgimento no final da década de 50, o uso de próteses como as de polipropileno para correção de hérnias de parede abdominal era exclusivo para cirurgias limpas, sendo muitas vezes contraindicado para cirurgias de emergência. Nas últimas décadas tem-se observado que tal prerrogativa está sendo quebrada. Muitas vezes o uso de tela é obrigatório e bem estabelecido na correção de hérnias,
Figura 1 - Hérnia umbilical, ulceração e evisceração (seta)

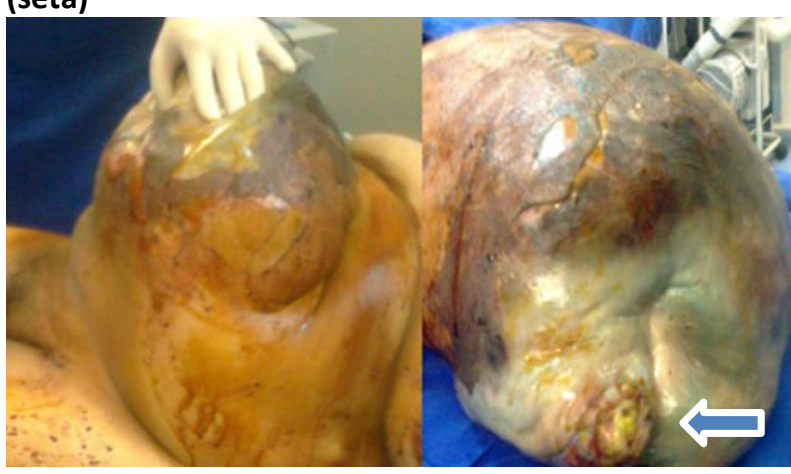

Figura 2 - Tomografia: hérnia umbilical gigante

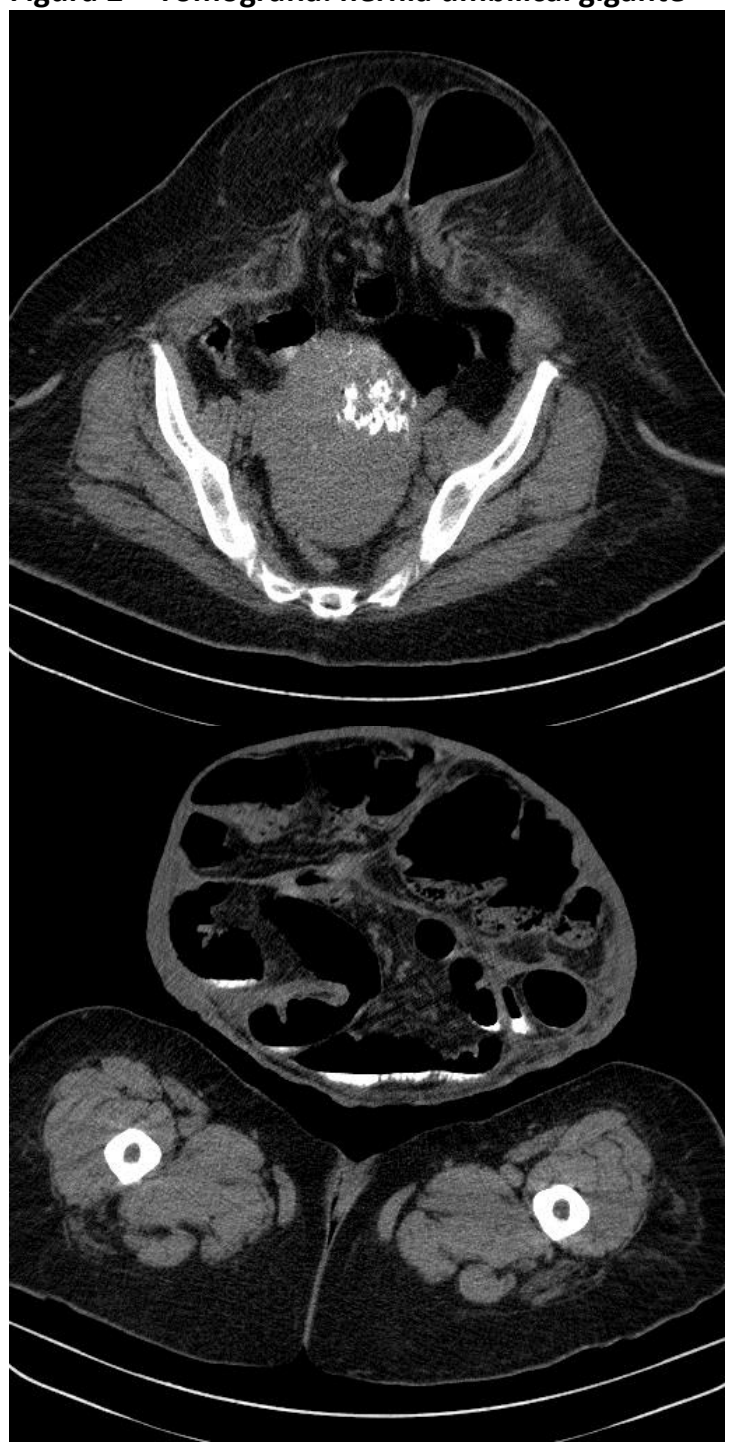

visando um fechamento sem tensão da parede abdominal. . Entretanto em cirurgias de urgência, onde há contaminação da parede abdominal, o risco de aplicação de próteses não está bem elucidado. Muitos estudos já relatam os benefícios do uso da tela, sem necessidade de realizar um segundo tempo cirúrgico, 
Figura 3 - Aspecto pós ressecção e herniorrafia

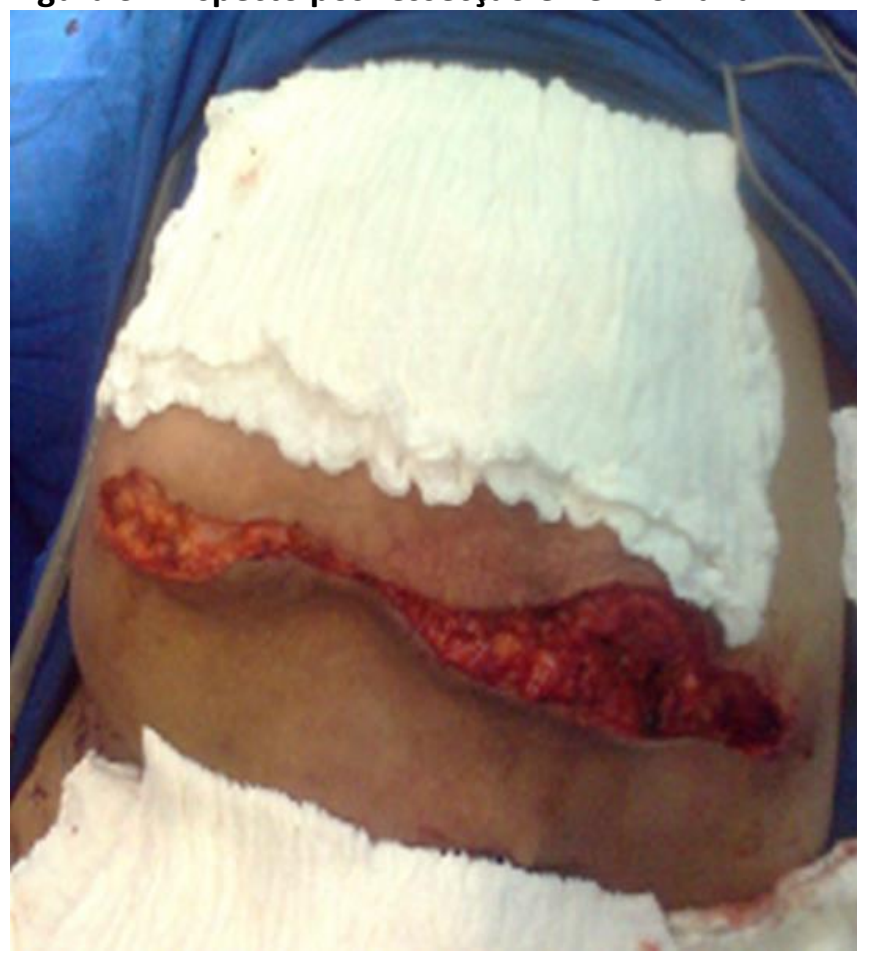

todavia ainda necessita-se de mais estudos prospectivos para tornar tal conduta um consenso ${ }^{4}$. Em consonância com a literatura, mesmo nos casos com contaminação pequena (ALTMEIER 2) do sítio operatório, pode-se aplicar uma tela nas grandes hérnias visando diminuir a tensão dos tecidos ${ }^{5}$. Embora se deva considerar que existe a possibilidade de infecção na incisão cirúrgica complicada pela presença do corpo estranho (tela), somente naqueles casos com grande contaminação como em peritonites purulentas e ou contaminação fecal franca é que estaria contraindicada a colocação da tela ${ }^{4-8}$.

\section{REFERÊNCIAS}

1.HALM, J.A.; HEISTERKAMP, J.; VEEN, H.F.; WEIDEMA, W.F. Long term follow up after umbilical hernia repair: are there risk factors for recurrence after simple and mesh repair. Hernia, 200; 9:334-7.

2.DABBAS, N.; ADAMS, K.; PEARSON, K.; ROYLE, G.T. Frequency of abdominal wall hernias: is classical teaching out of date? JRSM Short Rep, 2011;2(1):1-6.

3.MARTÍNEZ-SERRANO, M.A.; PEREIRA, J.A.; SANCHO, J.J.; LÓPEZ-CANO, M.; BOMBUY, E.; HIDALGO, J. Risk of death after emergency repair of abdominal wall hernias. Still waiting for improvement. Langenbecks Arch Surg, 2010;395(5):551-6.
4.BIROLINI, C.; UTIYAMA, E.M.; RODRIGUES JR, A.J.; BIROLINI, D. Elective colonic operation and prosthetic repair of incisional hernia: Does contamination contraindicate abdominalwall prosthesis use? J Am Coll Surg, 2000;191(4):366-72.

5.VIX, J.; MEYER, C.; ROHR, S.; BOURTOUL, C. The treatment of incisional and abdominal hernia with a prosthesis in potentially infected tissues - A series of 47 cases. Hernia, 1997;1(9):157-61.

6.WYSOCKI, A.; POZNICZEK, M.; KRZYWON, J.; BOLT, L. Use of polypropylene prostheses for strangulated inguinal and incisional hernias. Hernia, 2001;5(2):1056.

7.PANS, A.; DESAIVE, C.; JACUET, N. Use of a preperitoneal prosthesis for strangulated groin hérnia. Br J Surg, 1997;84(3):310-2.

8.CAMPANELLI, G.; NICOLOSI, F.M.; PETTINARI, D.; AVESANI, E.C. Prosthetic repair, intestinal resection, and potentially contaminated areas: Safe and feasible? Hernia, 2004;8(3):190-2. 